\title{
CONHECIMENTO, PRÁTICA PEDAGÓGICA E EDUCAÇÃO FÍSICA: APROXIMAÇÕES COM O CAMPO DA DIDÁTICA...
}

\author{
KNOWLEDGE, PEDAGOGICAL PRACTICE AND PHYSICAL EDUCATION: \\ APPROACHES TO THE FIELD OF DIDACTICS...
}

CONOCIMIENTO, PRÁCTICA PEDAGÓGICA Y EDUCACIÓN FÍSICA: APROXIMACIONES CON EL ÁMBITO DE LA DIDÁCTICA...

\section{Ricardo Rezer*}

Palavras-chave Conhecimento. Educação Física. Ensino.

Keywords Knowledge. Physical Education. Teaching.
Resumo: 0 objetivo deste texto é refletir acerca de nexos entre conhecimento e prática pedagógica na Educação Física (EF), perspectivando, a partir disso, aproximações com o campo da didática. Inicialmente, procuro esboçar uma compreensão de EF, entendendo-a como pano de fundo para as discussões pretendidas neste texto. Em um segundo momento, fomento algumas aproximações específicas com o campo da didática, abrindo espaço para pensar a EF nesta discussão. Finalmente, abordo alguns nexos entre conhecimento e prática pedagógica, a partir da tensão entre teoria e prática, discussão que considero central para pensar uma didática da EF.

Abstract: The aim of this paper is to reflect about links between knowledge and pedagogical practice in the field of Physical Education (PE), drawing approaches with the field of didactics. First, I describe a view about PE, taking it as the backdrop for discussions in this text. Then, I develop some specific approaches to didactics, opening room to think about PE. Finally, I discuss some connections between knowledge and pedagogical practice, based on the tension between theory and practice - a discussion I see as crucial to think about a didactics "of" PE.

Resumen: El objetivo de este trabajo es reflexionar acerca de los vínculos entre el conocimiento y la práctica pedagógica en el campo de la Educación Física (EF), buscando, a partir de ahí, aproximaciones con el campo de la didáctica. Inicialmente, intento esbozar una comprensión de la EF entendiéndola como telón de fondo para las discusiones pretendidas en este texto. En un segundo momento, fomento algunas aproximaciones específicas con el campo de la didáctica, abriendo espacio para pensar la EF en esta discusión. Por último, abordo algunos nexos entre conocimiento y práctica pedagógica, a partir de la tensión entre teoría y práctica, discusión que considero central para pensar una didáctica "de la" EF.
Universidade Comunitária da Região de Chapecó. Chapecó, SC, Brasil. E-mail: rrezer@ hotmail.com

Recebido em: 16-10-2014 Aprovado em: 04-04-2015 (c) (1) (8) Licence 


\section{CONSIDERAÇÕES INICIAIS ${ }^{1}$}

A constituição deste texto parte de uma simples mas provocadora questão: "o que temos a falar sobre didática no campo da Educação Física?". A questão manifesta uma inquietação frente ao tema, na mesma medida em que parece transparecer certa inconformidade ao estado de tal discussão no campo da Educação Física (EF). Ao enfrentá-la, o desconforto é evidente. Principalmente por permitir pensar sobre o quanto o cotidiano do trabalho docente é atravessado por questões didáticas - muitas delas despercebidas. Questões sobre como ensinar e aprender são ainda motivo de angústia no cotidiano de professores e professoras - certamente, não somente na $\mathrm{EF}^{2}$.

Partindo dessas considerações iniciais, o objetivo deste texto é refletir acerca de nexos entre conhecimento e prática pedagógica na EF, perspectivando, a partir disso, aproximações com o campo da didática. Na direção de enfrentar a complexidade do debate proposto, estruturei 0 texto em alguns momentos, todos interconectados entre si. Inicialmente, procuro esboçar uma compreensão de EF, com a qual venho trabalhando nos últimos anos, entendendo-a como pano de fundo para as discussões pretendidas neste texto. Em um segundo momento, procuro realizar algumas aproximações com o campo da didática, abrindo espaço para pensar a EF nesta discussão. Após, abordo alguns nexos entre conhecimento e prática pedagógica, a partir da tensão entre teoria e prática, discussão que considero como central para pensar uma didática da EF. Finalmente, apresento algumas sínteses derivadas das reflexões estabelecidas ao longo do texto.

\section{ESBOÇANDO UMA COMPREENSÃO DE EDUCAÇÃO FÍSICA...}

Neste tópico, procuro apresentar a compreensão de EF com a qual venho trabalhando, no sentido de edificar um pano de fundo para os tópicos posteriores. Porém, mais do que "definir" um conceito de EF, procuro evidenciar a partir de que base teórica a compreendo, bem como o projeto no qual me alinho para o desenvolvimento do campo. Frente à (feliz) impossibilidade de consenso interno sobre aspectos epistemológicos, axiológicos e teleológicos, o diálogo sobre estas questões pode permitir manter em movimento 0 (sôfrego) debate entre diferentes projetos históricos para a EF brasileira.

A metáfora de um mosaico, já utilizada por Hugo Lovisolo, permite evidenciar a diversidade de abordagens edificadas no interior do campo, conforme será exemplificado mais à frente. Tais abordagens apresentariam, em tese, diferentes proposições para responder a pergunta "o que é EF?". Ou seja, "definir" o conhecimento e as fronteiras do campo, bem como suas finalidades, é tema controverso, impregnado de disputas, tanto no plano epistemológico como no plano político. Bem verdade, por força de aspectos legais, alguns projetos estão em maior evidência na contemporaneidade.

Essa conjuntura reforça a necessidade que temos de discussão e reflexão sobre os caminhos da EF na contemporaneidade. Ou seja, trata-se de um campo do conhecimento constituído por diferentes "formas-de-ser", que se derivam em diferentes "Educações Físicas". Em

\footnotetext{
1 Uma versão simplificada deste texto, intitulada Conhecimento e prática pedagógica na Educação Física escolar: aproximações com 0 campo da didática... foi produzida e apresentada na forma de palestra no III Congresso Estadual de Educação Física na Escola, realizado na UNIVATES (Lajeado-RS), em maio de 2014.

2 Texto publicado na revista Nova Escola (n‥241, abr. 2011, p. 88) afirma que a "didática nunca recebeu a atenção que merece nos cursos de Pedagogia". Isso reforça a hipótese de que se trata de um tema pouco estudado em diferentes campos do conhecimento, talvez, por compreendê-lo como um tema de "segunda categoria". Tal ideia pode ter sido edificada a partir da noção de que estudar os processos de organização e sistematização do ensino e da aprendizagem são temas de menor importância, algo que "todos sabem".
} 
outro trabalho (REZER, 2014), abordo a configuração multifacetada do campo da EF que, via de regra, se interconecta com outros campos do conhecimento (Filosofia, Psicologia, Fsiologia, entre outros).

Tal diversidade vem sugerindo o que denomino "exercícios de classificação" da EF brasileira. Um desses exercícios é realizado por Palafox e Nazari (2007), que tiveram por objetivo descrever e analisar recentes abordagens de ensino da EF Escolar, buscando compreender sua trajetória histórica, bem como suas possibilidades e limites, articulando esta discussão com a formação continuada de professores das redes públicas de ensino.

Afirmam que, à luz das correntes epistemológicas do conhecimento científico, várias foram as abordagens constituídas na EF brasileira ao longo da sua história. No quadro a seguir, apresento algumas abordagens de ensino, na perspectiva dos autores, surgidas a partir dos anos 1970 e 1980 no Brasil, as quais continuam refletindo, social e politicamente, a pluralidade de entendimentos a respeito de quais "são" e/ou "devem ser" as "bases" epistemológicas, axiológicas e teleológicas para o ensino da EF na escola.

Quadro 1 - Abordagens teóricas da EF

\begin{tabular}{|l|l|c|}
\hline Abordagens & Representantes & Ano \\
\hline Aptidão Física & Victor Matsudo e outros & 1978 \\
\hline Humanista & Vitor Marinho de Oliveira & 1985 \\
\hline Concepção Aberta & Reiner Hildebrandt e outros & 1986 \\
\hline Psicomotora & Le Boulch e outros & 1986 \\
\hline Fenomenológica & Silvino Santin, Wagner Moreira & $1987,1990 / 92 / 93$ \\
\hline Desenvolvimentista & Go Tani e outros & 1988 \\
\hline Construtivista & João Batista Freire & 1989 \\
\hline Sociológica & Mauro Betti & 1991 \\
\hline Crítico-superadora & Valter Bracht e outros & 1992 \\
\hline Crítico-emancipatória & Elenor Kunz e outros & 1994 \\
\hline Cultural-plural & Jocimar Daólio & 1994 \\
\hline
\end{tabular}

Fonte: Adaptado de Palafox; Nazari (2007, p. 1)

Os autores reconhecem o significativo impacto social da produção de conhecimento decorrente dessas abordagens. Porém, reconhecem que elas não se manifestam no cotidiano escolar de forma homogênea ou consensual, e sim sob diferentes lógicas de intervenção (neste caso, a noção de bricolagem desenvolvida por Hugo Lovisolo parece ser pertinente).

Outros trabalhos foram realizados nessa direção, tais como os de Taffarel (1997), Castellani Filho (1999), Sanches Neto e Betti (2008), entre outros. Reconheço o esforço dos autores, mas entendo que é sempre polêmico e complexo enquadrar formas de pensar, pois elas são fluidas, não estáticas e representam sempre uma interpretação articulada com um aporte teórico anterior edificado na interlocução com outros campos do conhecimento. Assim, entendo tais "exercícios de classificação" apenas como um esforço interpretativo que pode "retratar", momentaneamente, a contemporaneidade da EF brasileira, não sem riscos.

Almeida, Bracht e Vaz (2012) fazem uma dura crítica às tentativas de classificação - no caso, referem-se a recentes classificações que denominam epistemológicas -, uma "moda" no 
campo da EF brasileira. Os autores propõem uma "redescrição" de duas classificações bastante utilizadas na EF. De um lado, a que considera a produção do conhecimento organizada em torno de três matrizes teóricas (empírico-analítica, fenomenológico-hermenêutica e crítico-dialética). De outro lado, a que opõe os denominados modernos e pós-modernos no debate epistemológico da área. Analisam a atualidade de ambas, quando se considera a configuração teórica e política do campo, bem como quando se opera uma leitura mais ponderada de determinadas perspectivas que integram tais classificações.

Almeida, Bracht e Vaz (2012) ainda criticam a ideia de tratar como "modismos" os novos paradigmas que escapam à classificação empírico-analítica, fenomenológico-hermenêutica e crítico-dialética, contra os quais se desencadeiam reações - neste caso, se referem especificamente aos trabalhos de Chaves e Gamboa (2011) ${ }^{3}$, Taffarel e Albuquerque (2010) e Gamboa (2010).

Ao longo do texto, sinalizam para as insuficiências e limites dessas classificações, desabonando os rótulos a partir delas desencadeados. A partir disso, se referem à complexidade do esforço de interpenetração de diferentes correntes teóricas, sugerindo maior cautela nas tentativas de classificação. Concordando com os autores,

Não consideramos inadequado o uso de classificações para caracterizar a produção do conhecimento da área. Reconhecemos que elas ajudam o leitor neófito não somente a se situar no debate, mas, também, a caracterizá-lo em função das perspectivas que o compõem. Elas se tornam questionáveis quando, ao invés de liberar o pensamento, inibem-no, mantendo-o preso a estereotipias que exercem um poder simplificador sobre o que se pretende elucidar. (ALMEIDA; BRACHT; VAZ, 2012, p. 258).

Em meio a esses argumentos, as dificuldades de atribuir um sentido e um significado mais claro, sistematizado e fundamentado à EF tem sido, via de regra, um desafio. Isso é evidenciado quando perguntamos, em nível de provocação, para estudantes e professores, "O que é EF?". A polissemia é significativa, e fica evidente o distanciamento entre a capacidade de resposta de muitos estudantes e professores e o conhecimento produzido e veiculado por diferentes comunidades da EF.

Certamente, "o que é EF?" não se trata de questão simples de ser respondida e merece todo cuidado. Porém, cabe perguntar, também, o que esperamos com a resposta. Uma resposta "definitiva"? Uma impossibilidade, em razão de que não há (felizmente) "alguém" com autoridade suficiente para isso. Então, nos sobram respostas provisórias, limitadas, que façam sentido a outros e dotem de sentido nossa percepção sobre o campo. Tal esforço nos coloca em outro patamar, pois nos permite, razoavelmente, perspectivar um projeto para o campo, a partir de nossa capacidade de elaboração conceitual, que nos permita maior autoridade frente aos desafios da EF.

Entendo que, se as palavras são fluidas, necessitamos aprender a nos entender sobre o significado com o qual queremos tratá-las, sob risco de uma polissemia se tornar regra, 0 que conduz a um relativismo que não me parece adequado para a $\mathrm{EF}^{4}$. Próximo do que afirma

3 CHAVES, Márcia; GAMBOA, Sílvio Sanches. A produção de conhecimento em EF/Ciências do Esporte/CE - qualidade x quantidade: os desafios de uma experiência concreta. Palestra proferida no IV Fórum de Pós-Graduação em Educação Física do CBCE. Florianópolis, 2011.

4 Talvez a noção de pensamento fraco constituída por Vattimo (2007) seja frutífera na discussão. Gianni Vattimo, filósofo italiano, propõe o que ele denomina pensamento fraco, frente ao pensamento forte. Ou seja, uma possibilidade de relativizar, porém, sem cair na armadilha de um "vale-tudo". O autor considera que a convicção é um problema em qualquer tempo (acrescento, em qualquer campo do conhecimento). Nessa direção, Vattimo entende o pensamento fraco como uma atitude (em seu entender, pós-moderna) que aceita e convive bem com o peso do erro e da diferença - sem dúvida, uma condição própria da finitude humana. Talvez, os argumentos apresentados na elaboração de Vattimo possam proporcionar elementos importantes para pensar a discussão ora proposta. No campo da EF, o prof. Valter Bracht vem chamando a atenção, também a partir de uma orientação hermenêutica, para o que ele denomina de relativismo fraco, frente a um pretenso relativismo 
Tugendhat (2007, p. 32), não tenho pretensões de apresentar o verdadeiro sentido das palavras (neste caso, "definindo" o que é EF), pois o mais importante é ter bem claro, entre os diversos significados possíveis que possuem, o significado com que se quer empregá-las.

De minha parte, sem pretensões de "enquadrar" a realidade, procuro edificar argumentos que me permitam transitar com maior segurança pela EF, "testando-os", na mesma medida em que vou procurando qualificar minha compreensão sobre o próprio campo. Nesse sentido, em meio à diversidade da EF contemporânea, compreendo-a como um campo do conhecimento que se caracteriza como uma prática pedagógica e científica, que tematiza e/ou investiga, com intenções pedagógicas, elementos da cultura corporal de movimento. Essa interpretação, baseada especialmente em aproximações com os trabalhos dos professores Valter Bracht, Mauro Betti e Paulo Fensterseifer, não "fecha" a discussão, mas pode nos permitir manter em movimento possibilidades de pensamento sobre o campo no qual trabalhamos em nosso cotidiano, independentemente do contexto de intervenção.

Desta forma, esses argumentos representam o pano de fundo das pretensões deste texto. Ou seja, as aproximações que penso possíveis entre EF e didática se edificam a partir desta inconclusa compreensão de EF, considerando a provisoriedade dos argumentos ora apresentados. A seguir, procuro desenvolver aproximações mais concretas com o campo da didática.

\section{APROXIMAÇÕES COM O CAMPO DA DIDÁTICA...}

Inicio este tópico lembrando um clássico na discussão sobre didática, a obra Didactica magna (Didática Magna), de João Amós Comenius (Jan Amos Komenský, 1592-1670), publicada em 1649. Nas palavras de seu autor, a obra se apresenta como um tratado da arte universal de ensinar tudo a todos. Nela, Comenius (1997, p. 45) se refere à didática como "a arte de ensinar" e procura apresentar orientações práticas para efetuar experiências que atualizem as potencialidades humanas.

Para tal empreendimento, sinaliza que os seres humanos possuem regularidades de desenvolvimento (tal como o desenvolvimento de árvores e plantas), necessitando de cuidado com 0 aprender, especialmente "na tenra idade" - no capítulo VII aborda isso: "A formação do homem faz-se com muita facilidade na primeira idade, e não pode fazer-se senão nessa idade" (COMENIUS, 1997, p. 127).

$O$ caminho proposto por Comenius, de acordo com Gasparin (1997), pode ser resumido em três princípios gerais: aprender com segurança, com facilidade e solidamente. "Traduzir" a obra de Comenius para nosso tempo representa um importante esforço, sob risco de exigir algo fora das possibilidades de autor e obra. Por isso, entendo que ela ainda se coloca na condição de inspiração importante para discussões de ordem didática na contemporaneidade.

Do ponto de vista conceitual, a discussão sobre didática se afirmou a partir das pretensões do projeto denominado "moderno" ${ }^{5}$, muito presente na obra de Comenius. Levar a sério questões da didática

\footnotetext{
seria a capacidade de entendimento pelo diálogo, como possibilidade de nos entendermos frente à diversidade do mundo (REZER, 2014). 5 Em síntese, o que é conhecido como "modernidade" e que se desenvolveu a partir do século XVII tem como principal característica a confiança otimista na razão, cujo modelo é principalmente dado pela matemática. Tem como marco, entre outros, a figura do filósofo, físico e matemático francês, contemporâneo de Comenius, René Descartes (1596-1650), que, a seu modo, revolucionou a filosofia e a ciência, propondo um deslocamento da leitura de mundo de um modelo pautado pelo dogma da fé para a autoinstituição do sujeito pelo uso da própria razão. A crença na razão, na ciência e no progresso ad infinitum, entre outros, são desdobramentos históricos da radicalização desse projeto. A escola, sem dúvidas, acompanhou esse movimento pari passu. Na contemporaneidade, a modernidade representa um projeto em crise e expressões tais como "pós-modernidade", "modernidade líquida", "alta modernidade" vão ganhando espaço. Mas isso é assunto para outro texto.
} 
representa uma perspectiva de, concordando com Wiggers (2005), intervenção deliberada dos adultos na educação das crianças - ao contrário de perspectivas educativas pautadas por certa espontaneidade da aprendizagem. Nesta direção, a didática passa a ocupar-se das questões de articulação entre ensinar e aprender, visando à organização e ao controle do processo educacional, de forma intencional e sistematizada.

Levada ao pé da letra, representou uma investida que pretendeu controlar o conteúdo, sua "dosagem", técnicas e métodos de ensino, etc. Tal investida, especialmente situada na metade do século passado, denominada didática prescritiva, atentou especialmente a questões técnicas de métodos e procedimentos.

A partir desse movimento, questões como planejamento, execução e avaliação do ensino e de seus elementos básicos (objetivo, aluno, professor, matéria e método) passam a representar importantes elementos nos processos de ensino-aprendizagem. Tais preocupações se referem a esforços significativos na direção de permitir maior controle do processo educativo. Como contraponto, isso levou a um movimento denominado "antididática", caracterizado pela negação da perspectiva anterior, bem como pela ênfase na relação entre ser humano, educação e sociedade. (WIGGERS, 2005, p. 135). Aqui, aspectos de ordem micro (aula, conteúdo, objetivos, etc.) cedem lugar para aspectos de ordem macro (sociedade, política, etc.), fenômeno que não deixa incólumes campos como a EF.

Derivada desse movimento, a didática ressurge como uma "nova didática" em meados de 1980. Essa nova perspectiva se caracterizou como sendo um "conjunto de conhecimentos específicos que se situam no campo de articulação entre o conhecimento sistematizado e o conhecimento escolar, entre as práticas produtivas da sociedade como um todo e as práticas pedagógicas escolares". Questões como "compromisso com as classes populares", "transformação social", entre outras, tomam forma nesse momento (WIGGERS, 2005). Cabe lembrar a articulação desse movimento com o processo de democratização da sociedade brasileira a partir do momento de abertura política que o país atravessava.

Como referido anteriormente, a EF não passa à margem disso. Neste caso, publicações como Introdução à didática da educação física (FARIA JUNIOR, 1969), Visão didática da Educação Física (VISÃO..., 1991), Didática da educação física (CAMPOS, 2011), entre outras, apontam para possibilidades frente a esta discussão em diferentes momentos históricos do campo. Se a didática se traduz no estudo e na organização/sistematização do processo de ensino e aprendizagem, a partir dos elementos que constituem a intervenção pedagógica (professor, aluno, conteúdo, objetivo, método, contexto, cultura, entre outros), ao pensarmos a EF como disciplina escolar, não é difícil nos percebermos cercados de questões vinculadas ao campo da didática - especialmente se tomarmos como referência a compreensão de EF apresentada no tópico anterior. Questões como "quem aprende?", "quem ensina?", "para quê ensinar?", "o quê e como ensinar?", "quando ensinar?" ainda são questões que devem ser respondidas em cada contexto de intervenção, quer seja na escola, quer seja na universidade - arrisco afirmar que tal pressuposto se estende a todo contexto com pretensões pedagógicas, ou seja, contextos em que existe alguém instituído como professor que pretende ensinar algo a alguém (escolinhas, academias, entre outros).

Entendo que significativa parcela dos problemas enfrentados no cotidiano da intervenção pedagógica de professores e professoras de EF se edifica a partir da dificuldade em enfrentar questões como as expressas no parágrafo anterior. Certamente não são questões simples que 
devem ser enfrentadas: a) pelo professor; b) pelo contexto específico da intervenção; c) pelo campo da EF a partir de suas aproximações com o campo da Educação (especificamente, neste caso, com a didática).

Enfrentar essas questões é tarefa inerente ao trabalho docente, independente do contexto de intervenção. Porém, enfrentá-las individualmente representa tarefa quixotesca. A escola e a universidade, como instituições republicanas, necessitam discutir e estudar sobre isso na condição de esforço coletivo. Um desafio de fundo ainda a superar é edificar condições objetivas para isso, o que alça os desafios evidenciados também ao plano da política. Estratégias pensadas por professores e gestores podem permitir a construção de uma agenda comum para enfrentar desafios comuns. No que toca ao campo da $\mathrm{EF}$, sem dúvida, percebemos uma tradição ainda recente de enfrentar esse desafio no cotidiano. Estudar 0 próprio trabalho, desafios, paradoxos e aporias dele derivados ainda não representa uma preocupação intrínseca ao trabalho docente no campo da EF.

$\mathrm{Na}$ direção de enfrentar esses desafios, vemos crescer trabalhos que sinalizam a produção de pesquisas colaborativas como uma possibilidade significativa de aproximar universidade e escola, bem como pensar a produção de respostas a partir da interlocução entre colegas que trabalham em diferentes contextos, mas que podem ter preocupações em comum. Os trabalhos de Bracht et al (2003), Caparroz e Bracht (2007), Betti (2009), entre outros, sinalizam para isso, considerando a importância do professor se debruçar como pesquisador de sua própria prática, considerando, para tal, aproximações com professores de diferentes contextos (escola, universidade, entre outros). Isso permite transformar problemas do mundo em problemas de pesquisa, ampliando as possibilidades de lidar com eles.

Assim sendo, se faz necessário levar esta discussão aos cursos de formação em EF. Tratar as aproximações entre EF e didática como um conhecimento que atravessa as diferentes disciplinas na formação representa um esforço de alçar a discussão proposta a um patamar que a coloca para muito além de disciplinas específicas dos processos de formação - geralmente Didática e Didática da EF. Pensar, por exemplo, como esta discussão pode se dar nas disciplinas vinculadas ao campo do esporte (especialmente as disciplinas específicas) representaria um salto nos processos de formação.

A seguir, procuro apresentar alguns nexos entre conhecimento e prática pedagógica, discussão que considero como central para pensar uma didática da EF.

\section{NEXOS ENTRE CONHECIMENTO E PRÁTICA PEDAGÓGICA NO CAMPO DA EF...}

Em outro trabalho (REZER, 2014), me refiro à recente tradição teórica do campo da $E F$, possivelmente derivada da noção de que se trata de um campo que lida exclusivamente no plano da ação (ou seja, com a "prática"). Certamente, várias tentativas vêm se desenvolvendo na EF brasileira a fim de avançar frente a essa limitada compreensão. $O$ fato de o campo ter sido alçado à condição de área do conhecimento junto à Coordenação de Aperfeiçoamento de Pessoal de Nível Superior (Capes) e ao Conselho Nacional de Desenvolvimento Científico e Tecnológico (CNPq) representa elementos importantes nesse reconhecimento, além de possibilitar financiamento de pesquisas, fomento à produção do conhecimento, auxílios e bolsas, entre outros. 
Sem contar que a pós-graduação stricto sensu representa uma possibilidade significativa de qualificação para os trabalhadores da EF - em 2014-I, são 32 programas de pós-graduação, sendo 19 doutorados, 31 mestrados acadêmicos e um mestrado profissional na Área 21 (Capes). Nessa esteira, a produção intelectual da EF, assim como das demais 47 áreas do conhecimento alocadas na Capes, vem crescendo de forma muito significativa ${ }^{6}$.

Em meio a esse incremento, percebemos distanciamentos importantes entre a produção e os profissionais que atuam em diferentes contextos - no caso específico deste texto, no âmbito da EF brasileira. Como exemplo, ao observarmos aulas de EF em diferentes espaços (inclusive na universidade), em alguns casos, temos a impressão de que não conseguimos avanços significativos no desafio de "dar uma boa aula".

Nesse sentido, ao que parece, a significativa ampliação da produção acadêmica ainda se encontra distante para muitos, por diferentes razões. Não me coloco do lado daqueles que veem a produção do conhecimento como sinônimo de publicação de papers. Porém, a produção do conhecimento também se dá por meio de sua veiculação em trabalhos na forma de artigos publicados em periódicos e livros, entre outros. Então, devemos pensar em possibilidades mais concretas de aproximar os professores de EF desta produção, bem como fomentar a ideia de que somos potenciais protagonistas desta produção.

Ao abordar este assunto, percebemos que, por um lado, a EF brasileira, tal como outras áreas do conhecimento, vem ampliando sua produção intelectual significativamente. Por outro lado, questões básicas, tais como as apresentadas no tópico anterior, ainda não receberam a devida atenção da comunidade acadêmica (quem aprende, quem ensina, quando ensinar). Se a EF se constituiu como um campo capaz de analisar questões macro (políticas públicas, aproximações com teóricos consagrados, entre outros temas), ainda tem muito a investigar sobre questões micro (a aula, seleção de conteúdos, entre outros).

Este cenário contemporâneo, brevemente apresentado, nos remete às complexas relações entre teoria e prática, o que permite pensar: a) isso é extremamente problemático, no sentido de que o aumento da dita produção intelectual (teoria) não vem se desdobrando em melhoria das respostas necessárias ao cotidiano da intervenção docente (prática); b) parece haver uma excessiva expectativa com relação à produção teórica do campo, como se ela, ao ser "aplicada", pudesse derivar respostas mais qualificadas no cotidiano (causa-efeito).

Em meio a essas perspectivas, cabe perguntar: o que esperamos da dita "teoria"? E, nessa esteira, do conhecimento produzido e veiculado na forma de artigos, livros, teses e ou dissertações? Estaríamos, com isso, supervalorizando a produção (teórica), tal como se a ela coubesse "resolver" os problemas do campo? Podemos "resolver" problemas da prática com soluções de ordem teórica? Certamente, enfrentar essas questões necessita de um "passo atrás", ou seja, de um movimento epistemológico regressivo.

Para Bracht (2007, p. 82) a concepção de "teoria" ainda é compreendida como algo que deve ser "aplicado" por quem está na prática. Tal perspectiva hierárquica leva a crer que "[...] aqueles que estão na intervenção apenas aplicam ou deveriam aplicar o conhecimento produzido; aliás, que seriam bem sucedidos se aplicassem conhecimento científico".

6 Como exemplo, de acordo com dados da própria Capes, no triênio de avaliação 2007-2009, foram publicados 284.983 artigos completos em periódicos técnico-científicos, nas diferentes áreas do conhecimento. Já no triênio 2011-2013, este número saltou para 448.264, 0 que representa um aumento de aproximadamente $60 \%$, quando comparado com o triênio anterior. Ainda, se considerarmos a "produção intelectual" de todas as 48 áreas do conhecimento Capes no triênio 2011-2103, foram produzidos 1.498 .111 produtos (por produto, entende-se artigos publicados em periódicos, livros e produção técnica). 
Neste aspecto, teoria passa a ser vista como uma ameaça àqueles que não dominam determinadas análises aproximadas dos campos das Ciências Naturais, da Filosofia, entre outros, o que produz uma nova dicotomia entre os planos teórico e prático - "os antigos professores eram práticos e sabiam dar aula. Os novos são mais teóricos e não sabem dar aula" (CAPARROZ; BRACHT, 2007).

De minha parte, venho trabalhando com a ideia de que teoria se refere a nossa capacidade explicativa de elaborar argumentos sobre os fenômenos que compõem aquilo que entendemos por realidade, edificados a partir de critérios de justificação. Ou seja, teorizar se refere a nossa capacidade de construir argumentos sobre o mundo que façam sentido (a nós e aos outros), como uma possibilidade humana que permite qualificar nossa mirada, na mesma proporção que permite ampliar nossa compreensão sobre aquilo que fazemos. Isso representa uma oportunidade de qualificar nossas possibilidades de intervenção nas "coisas" do mundo, mediante nossa própria qualificação. Ao levar a sério esses argumentos, nossa capacidade de teorização representa uma possibilidade significativa de intervenção naquilo que denominamos "realidade da EF".

Nesta discussão, qual o sentido de falar em prática? Historicamente, podemos afirmar que a "prática" representa uma dimensão mais próxima da tradição da EF. É possível inferir que tal perspectiva diminui a noção de teoria, levando-a a um patamar de possibilidade ilusória de resolução dos problemas, descolada do mundo. Neste caso, é possível inferir que, muitas vezes, a própria compreensão sobre "prática" apresenta uma pretensão de diminuir a importância da teoria em nome de uma tentativa de evidenciar a experiência como fator determinante para 0 exercício profissional - nesta compreensão, experiência se adquire na "prática".

Se entendermos "prática" como uma intervenção do sujeito no mundo, uma ideia, um texto, uma teoria, etc., também podemos representar intervenções concretas (portanto práticas) na realidade do mundo. Isso nos ajuda a abandonar a noção de que teoria se aplica na prática, tal como Caparroz e Bracht (2007) se referem. Inclusive, permite alçar a prática também a uma forma valorizada de relação com o mundo e com os outros, importante pela possibilidade de encontro que toda experiência genuína propicia.

Assim, teoria e prática podem ser representadas como unidades de reciprocidade dialéticas, que convivem em um movimento de tensão radical. Concordando com Marques (2003, p. 93), "A teoria nega a prática em seus imediatismos, assim como a prática nega a teoria dela desvinculada, exigindo-se ambas em reciprocidade ao negarem-se uma a outra". Assim, ao professor de EF não basta aplicar teoria na prática, mas, sim, se colocar na condição de um intelectual da docência, que estuda, interpreta e produz enfrentamentos frente aos problemas do mundo, tomando como referência sua experiência e o conhecimento do próprio campo ou de campos aproximados. Isso promove um movimento nevrálgico para a docência: "testamos" a teoria na prática, na medida em que "testamos" prática na teoria.

Certamente, essa perspectiva de interpretação sobre teoria e prática, a partir dos argumentos apresentados acerca do afastamento entre o conhecimento produzido pela EF e diferentes processos de intervenção, não resolve as questões apresentadas. Porém, nos permite analisá-las com maior cuidado, submetendo-as a nossa capacidade de crítica, aqui entendida como a capacidade de inspeção, alicerçada em argumentos de justificação que nos possibilitem discernimento frente a nossas escolhas e análises. 
Portanto, concordando com Fensterseifer (2009) baseado em Maldaner, enfrentar essa discussão representa perceber a EF como produção e, seu ensino, como sendo uma compreensão/interpretação dessa produção. Levar a sério isso representa entender que avanços frente às relações entre conhecimento e prática pedagógica exigem a compreensão da produção do conhecimento do campo. Lembrando Kunz, citado por Fensterseifer (2009), "Somente se nós mesmos percebermos como nosso saber e nossa cultura são formados, esse saber ou essa cultura poderá nos formar".

Desta forma, fica o compromisso de aproximar a articulação entre aquilo que Kunz (2001) denominou de saberes para o esclarecimento e saberes para o agir prático. Conforme 0 autor, deste afastamento decorre termos poucos conhecimentos esclarecedores sobre aspectos fundamentais da EF, o que deriva o surgimento de poucas soluções para os problemas práticos do próprio campo.

Assim, derivado da falta de aprofundamento frente a determinados temas do cotidiano do trabalho docente no campo da EF (algo próximo do que venho denominando esvaziamento do conceito), elementos estruturantes da didática vão ocupando lugar periférico nos processos de formação e na produção acadêmica do próprio campo. Levar a sério esta discussão nos diferentes processos de formação (inclusive na pós-graduação) representa desafio do qual não podemos nos abster. Talvez assim produção do conhecimento e prática pedagógica possam "conviver" de maneira mais densa e radical, imersas na inerente e complexa tensão (irresolvível) que tal processo pressupõe.

\section{CONSIDERAÇÕES FINAIS...}

Aproximações entre universidade e escola, para além do campo burocrático, representam possibilidades para a qualificação de respostas frente a problemas históricos no movimento de pensar uma didática da EF - edificar condições objetivas para isso representa tarefa nada fácil que nos cabe enfrentar.

Nesta esteira, entendo que levar a sério a construção de projetos curriculares para 0 ensino daEF permite maior segurança, quer seja do ponto de vista epistemológico (conhecimento da EF), quer seja do teleológico (finalidades da EF), o que implica aproximações com a ética e a política. Como desdobramento disso, o processo de organizar/planejar/sistematizar 0 processo educativo passa a representar assunto nevrálgico para pensarmos uma didática da EF. Neste caso, aproximações com o campo da didática são essenciais, já que uma ampliação do estudo da didática representaria uma possibilidade de qualificar respostas que professores vêm construindo em diferentes contextos de intervenção.

Sem dúvidas, esse esforço não se dá em "etapas" (como, por exemplo, primeiro estudar para depois "por em prática"), mas, sim, em um movimento dialético e tenso entre teoria e prática, procurando radicalizar as relações entre conhecimento e prática pedagógica. Se a teoria pode ser representada por nossa capacidade explicativa frente às "coisas" do mundo, a prática deve ser colocada no patamar de uma possibilidade concreta de intervenção e reflexão de nosso próprio trabalho.

Sem dúvidas, enfrentar esse desafio é qualificar e contribuir com a construção de uma cultura da EF para ensinar elementos da cultura corporal de movimento. Como desdobramento 
desse processo, o estudante passa a "olhar" para a EF como uma disciplina escolar e/ou campo constituído de conhecimentos importantes para a vida, o que dota de sentido a noção de que ele tem algo a aprender com a EF.

Talvez, evidenciando as especificidades do próprio campo, seja possível avançar nesta discussão reconhecendo que, junto com a literatura, a música e a arte, a EF representa possibilidades concretas de contribuir para o cultivo de um bem viver ao longo da vida. Desta forma, aprender sobre a cultura corporal de movimento, na direção de aprender a ter boas relações com a dança, o esporte, a ginástica, com o próprio corpo, ao longo da vida, significa projetar uma dimensão importante da vida humana que exige cultivo, conhecimento e experimentação, como possibilidade de diálogo consigo mesmo, com os outros e o mundo.

Assim, a didática representaria uma possibilidade de estudar a organização deste processo de ensinar EF, considerando-a como um conhecimento importante para a vida. Portanto, qualificar nossa compreensão sobre o campo da EF possibilita desenvolver aproximações mais qualificadas com o campo da didática geral e com elementos específicos de uma didática para a EF. Nessa direção, fomentar nexos entre conhecimento e prática pedagógica se constitui como elemento central para redimensionar as relações entre teoria e prática no campo da EF.

Concordando com Fensterseifer (2009), se nosso compromisso resumia-se a um fazer, hoje somos desafiados a construir um saber articulado a esse fazer. Assim, as tensões que se desdobram deste esforço permitem retomar a importância da didática como um elemento necessário à intervenção pedagógica, que necessita de estudo, sistematização, projetação, tal como o esforço de um arquiteto que projeta sua obra. Não se trata de tarefa fácil, mas se nos colocamos na condição de profissionais da educação, professores de EF, autores de nosso trabalho, não há remédio. Não é possível alcançar a maioridade sem dor. Porém, penso que a dor de enfrentar desafios como os que aqui são expressos se diluirá, na medida em que considerações finais como as que ora apresento não fizerem mais sentido, pois tais aspectos irão se constituir "organicamente" no cotidiano do trabalho docente do professor de EF. A partir deste horizonte, é possível afirmar, considerando a questão apresentada logo na introdução, que ainda temos muito a dizer sobre didática no campo da EF.

\section{REFERÊNCIAS}

ALMEIDA, Felipe Quintão; BRACHT, Valter; VAZ, Alexandre Fernandes. Classificações epistemológicas na Educação Física: redescrições... Movimento, Porto Alegre, v. 18, n. 4, p. 241-263, out/dez de 2012.

BETTI, Mauro. Educação física escolar: ensino e pesquisa-ação. ljuí: Unijuí, 2009.

BRACHT, Valter et al. Pesquisa em ação: educação física na escola. ljuí: UNIJUÍ, 2003.

BRACHT, Valter. O CBCE e a Pós-Graduação stricto sensu da educação física brasileira. In: CARVALHO, Yara Maria; LINHALES, Meily Assbú. (Org.). Política científica e produção do conhecimento em Educação Física. Goiânia: Colégio Brasileiro de Ciências do Esporte, 2007. p. $73-85$. 
CAMPOS, Luís Antônio Silva. Didática da educação física. Jundiaí: Fontoura, 2011.

CAPARROZ, Francisco Eduardo; BRACHT, Valter. O tempo e o lugar de uma didática da Educação Física. Revista Brasileira de Ciências do Esporte, Campinas, v. 28, n. 2, p. 21-37, 2007.

CASTELLANI FILHO, Lino. A educação física no sistema educacional brasileiro: percursos, paradoxos e perspectivas. Tese (Doutorado em Educação Física) - Faculdade de Educação, Universidade de Campinas, Campinas, 1999.

COMENIUS, João Amós. Didática magna. Lisboa: Martins Fontes, 1997.

FARIA JUNIOR, Alfredo Gomez. Introdução à didática de educação física. Brasília: MEC, 1969.

FENSTERSEIFER, Paulo Evaldo. Epistemologia e prática pedagógica. Revista Brasileira de Ciências do Esporte, Campinas, v. 30, n. 3, p. 203-214, 2009.

GAMBOA, Sílvio Sanchez. O debate da pós-modernidade: as teorias do conhecimento em jogo. Filosofia e Educação: Revista Digital do Paidéia, Campinas, v. 2, n. 2, p. 74-98,out. 2010.

GASPARIN, João Luís. Comênio: a emergência da modernidade na educação. Petrópolis: Vozes, 1997.

MARQUES, Mário Osório. Formação do profissional da educação. ljuí: UNIJUÍ, 2003.

PALAFOX, Gabriel Humberto Muñoz; NAZARI, Juliano. Abordagens metodológicas do ensino da educação física escolar. Revista Digital, Buenos Aires, v. 12, n. 112, 2007. Disponível em: $<$ http://www.efdeportes.com/efd112/abordagens-metodologicas-do-ensino-da-educacao-fisica-escolar.

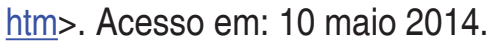

REZER, Ricardo. Educação física na educação superior: trabalho docente, epistemologia e hermenêutica. Chapecó: Argos, 2014.

SANCHES NETO, Luiz; BETTI, Mauro. Convergência e integração: uma proposta para a educação física de $5^{\underline{a}}$ a $8^{\underline{a}}$ série do ensino fundamental. Revista Brasileira de Educação Física e Esporte, São Paulo, v. 22, n. 1, p.5-23, jan./mar.2008.

TAFFAREL, Celi Nelza Zulke. Perspectivas pedagógicas em educação física. In: GUEDES, Onacir Carneiro (Org.). Atividade física: uma abordagem multidimensional. João Pessoa: Ideia, 1997.p106-130.

TAFFAREL, Celi Nelza Zulke; ALBUQUERQUE, Joelma de Oliveira. Epistemologias e teorias do conhecimento em educação e educação física: reações aos pós-modernismos. Filosofia e Educação: Revista Digital do Paidéia, Campinas, v. 2, n. 2, p. 8-52, out. 2010.

TUGENDHAT, Ernest. Lições sobre ética. 6. ed. Petrópolis: Vozes, 2007.

VATTIMO, Gianni. 0 fim da modernidade: niilismo e hermenêutica na cultura pós-moderna. 2. ed. São Paulo: Martins Fontes, 2007.

VISÃO didática da Educação Física: análises críticas e exemplos práticos de aulas. Rio de Janeiro: Ao Livro Técnico, 1991.

WIGGERS, Ingrid Dietrich. Didática. In: GONZÁLEZ, Fernando Jaime; FENSTERSEIFER, Paulo

Evaldo. (Org.). Dicionário crítico de educação física. ljuí: Unijuí, 2005. p. 133-136. 